\title{
Rimigs: the impact of gamification on students' motivation and performance in programming class
}

\author{
Ferdian Aditya Pratama ${ }^{1}$, Riana Magdalena Silitonga ${ }^{2}$, Yung-Tsan Jou ${ }^{3}$ \\ ${ }^{1}$ Department of Information System, Atma Jaya Catholic University of Indonesia, Jakarta, Indonesia \\ ${ }^{2}$ Department of Industrial Engineering, Atma Jaya Catholic University of Indonesia, Jakarta, Indonesia \\ ${ }^{2,3}$ Department of Industrial and Systems Engineering, Chung Yuan Christian University, Taoyuan, Taiwan
}

\begin{tabular}{l} 
Article Info \\
\hline Article history: \\
Received May 11, 2021 \\
Revised Oct 23, 2021 \\
Accepted Oct 27, 2021 \\
\hline
\end{tabular}

\section{Keywords:}

Game elements

Gamification

Motivation and performance

Octalysis framework

Rimigs

\begin{abstract}
Gamification is described as the art of changing human activity to a gamelike environment to gain user engagement. Rimigs is a developed gamification system discussed in this research and was built based on Octalysis framework. This research aims to design and identify the impact of using a gamification system on students' motivation and performance, especially in programming classes. Through Rimigs, students' engagement and performance can be enhanced by freely choosing tasks or quests according to the rank points, completing these tasks or quests, getting experience points, getting rewards, avoiding punishment at certain times, and competing with others friends. The proposed research was done by using the iterative methodologies and consists of four phases, starting from i) literature review, which identifies the Octalysis' core, ii) design, which identifies the game elements used in the system and designing the unified modeling language (UML) diagram of the system, iii) testing, which involve the user in the using of the system, and iv) implementation, which is the analysis step for the impact of Rimigs in students' performance and engagement. This research finds that Rimigs as a gamification system can positively impact both students' motivation and performance.
\end{abstract}

This is an open access article under the CC BY-SA license.

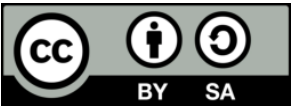

\section{Corresponding Author:}

Ferdian Aditya Pratama

Department of Information System

Atma Jaya Catholic University of Indonesia

Jendral Sudirman 51 St., Jakarta, Indonesia

Email: ferdian.aditya@atmajaya.ac.id

\section{INTRODUCTION}

Gamification is described as "the art of taking fun and engaging elements found in games and applying them thoughtfully to real-world or productive activities" [1]. Particular research said gamification is a concept of changing human activity to a game-like environment, enabling cognitive, affective, social, and motivational benefits [2]. A gamification software aims for high functionality and engagement [3] because humans have an innate pleasure to play [3]. Many people think gamification is only about points and badges instead of seeing it as a practical tool or learning [4]. Gamification has been used for many purposes and consists of a motivational system design that involves understanding motivational psychology [5]. The market predicted that the gamification size would be reaching \$934 million in 2022 [6]. The fun characteristic of the game is the primary element that makes gamification itself can be implemented in various ways, especially in the learning process or knowledge-sharing process [7].

When used in education, it inspires and engages students through game design concepts [8]. Implementing gamification in education refers to the using of gameful experience in the learning process [9], 
and it's not required to use an expensive technology device [10]. Gamification strategies are being used more commonly to positively impact actions and cognitive functions by improving a device or service with motivational affordances and, ultimately, by bringing similar experiences to those found in games [11]. Gamification can be combined with flipped learning method to improve the teaching and learning environment [12]. Several game elements are usually used in educational contexts, such as badges, leaderboards, rewards, storylines, and progress bars [13]. Although those game elements seem effective in the academic context, designing gamification must be cautious since it will affect students' learning experience [14]. Therefore, it is essential to understand the working mechanism of gamification itself [15].

As a result of the pandemic caused by the Coronavirus disease 2019 (COVID-19), viruses made a significant difference in every industry field, especially in education [16]. The maximum use of technologies these days is inescapable, especially in the learning process [17]. The learning process that was initially carried out face-to-face has now turned online. One of the private universities affected by the Covid-19 pandemic is Atma Jaya Catholic University of Indonesia. The pandemic situation is forcing the university to conduct the learning process entirely online. As for the "practical" department, such as Information Department, the entire online class can give the students a hard time understanding and engage in the class. The preliminary survey was conducted on the Information System Department in Atma Jaya Catholic University of Indonesia. Based on the study, the changing class environment affects the students' motivation and performance. Around $72 \%$ of students have demotivated and deterioration in their class performance, especially in programming class. One of the solutions to increasing the students' performance and motivation is by using gamification [18].

Rimigs is a gamification system designed for increasing students' engagement and motivation in the class. Rimigs was developed based on Octalysis framework, and it has several game elements like avatar, quest, experience, level, rank, leaderboard, achievements, and reward. Through Rimigs, students can freely choose tasks or quests according to the rank points, complete these tasks or quests, get experience points, get rewards, avoid punishment at certain times, and compete with other friends. The purpose of this research is to develop web-based gamification based on Octalysis framework. The result of this research is a web-based gamification system and how students become more engaged in class.

Another research finds the gamification approach has a positive effect on enjoyment toward knowledge sharing [19]. Even though gamification plays an essential role in education, there is still a lack of adequate guidelines for combining various gamification features to improve learning success in various educational contexts [20]. Another previous research affirms that using gamification in practical subjects can generate a better learning process [21]. The majority of review articles on the efficacy of gamification are constructive, listing either positive or mixed outcomes of gamified methods that have been implemented [22].

Previous research discussed the role of gamification for education on changing human behavior to become more pro-environmental. There are two frameworks used in this study: Octalysis and climate change engagement through the game framework. The study found by implementing both intrinsic and extrinsic elements on the gamification design, the behavior change of humans to become more pro-environmental is possible [23]. Another previous study discussed the use of Kahoot as a gamification platform to enhance students' motivation, engagement, and meaningful learning. The study was conducted with quasiexperimental methodologies with 101 undergraduate students as the participants. The study found that by integrating the game elements into the teaching process, it can enhance students' perception, motivation, their active participation in the class [24].

Another previous research discussed the design and development of Gamified content for basic Java computer programming. The system was designed based on the Octalysis framework too. The gamification system was built using hypertext markup language (HTML) 5 for its language. The Octalysis score is 6 out of 7 and has a good motivation for learning. Also, the gamification system has a balanced extrinsic and intrinsic motivation for students [25].

\section{RESEARCH METHOD}

This research uses the iterative model in its work. The iterative development model splits the software development of a broad application into smaller chunks. As a result, it's thought of as the method of breaking down an extensive application's software creation into smaller chunks [26]. The uses of the iterative model in this research are shown in Figure 1.

A literature review of the Octalysis framework started the requirement step. There are eight core drives on it i) meaning, ii) accomplishment, iii) empowerment, iv) ownership, v) social influence, vi) scarcity, vii) unpredictability, and viii) avoidance. A preliminary survey was also conducted to identify the current problem that students faced in the online class. 
The design process was conducted to identify what kind of game elements will be used in this research and how to design the game mechanics based on Octalysis framework. Based on the analysis, the design gamification system is focusing on improving intrinsic students' motivation. In this step, system design also conducted using a unified modeling language (UML) diagram. There are three main actors in this system lecturer, lecturer assistant, and students. The main activity for student actors is taking some quest based on their current subject on Rimigs. The lecturer assistant's main activity is grading students' quests and can't either add, update, or delete quests posted by Lecturer. Rimigs analysis using the Octalysis framework is shown in Figure 2.

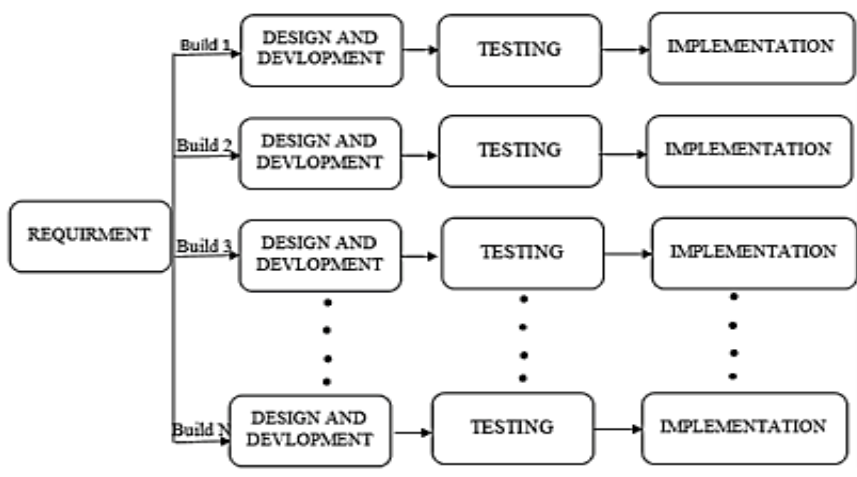

Figure 1. Iterative model

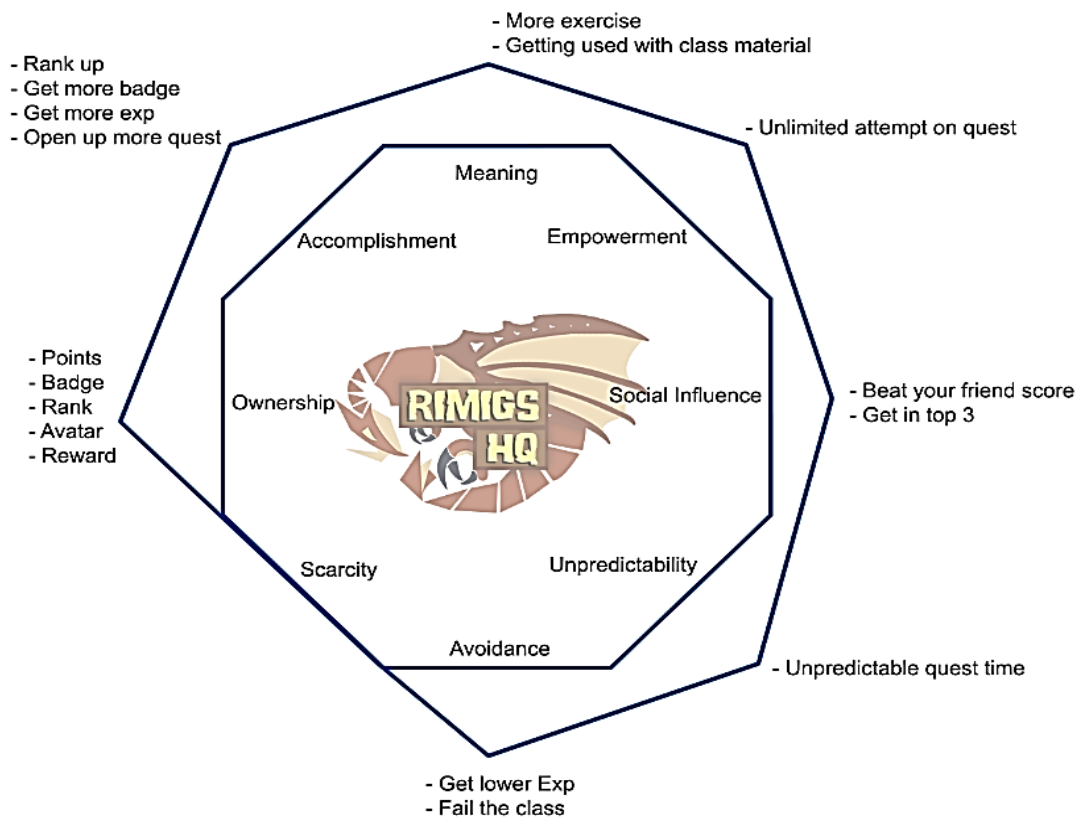

Figure 2. Gamification analysis using Octalysis framework

Rimigs has a significant gap in ownership and accomplishment core, but it still lacks the scarcity core. The accomplishment core focuses on players' progress and developing skills. On the other hand, the ownership core focus on players' possession of the system. Both accomplishment and ownership are the types of extrinsic motivation. Rimigs also have some points in the right-side core, such as empowerment, social influence, and unpredictability. Those cores are the type of intrinsic motivation.

Based on the Octalysis framework analysis, Rimigs is a gamification system that extrinsically increases user motivation. Even though the scarcity core is still missing, both accomplishment and ownership core still have the most significant score than other cores. Rimigs not only focusing on increasing motivation extrinsically but also intrinsically. Both extrinsic and intrinsic motivation were applied in Rimigs, but the extrinsic side (left-side core) has a more significant score than the intrinsic (right-side core) score. The use case of Rimigs is shown in Figure 3.

Rimigs: the impact of gamification on students' motivation and performance... (Ferdian Aditya Pratama) 
The testing process was conducted both functional and non-functional testing. The functional testing was performed using the black box testing technique, and the non-functional testing was conducted quantitatively using the questionnaire to 53 samples. The questionnaire was distributed to identify students' motivation and performance in the programming class. The development process was conducted based on the designing system in the previous step. Rimigs was developed by using PHP framework laravel 7 and use my structured query language (MySQL) for the database. The user interface of Rimigs is shown in Figure 4.

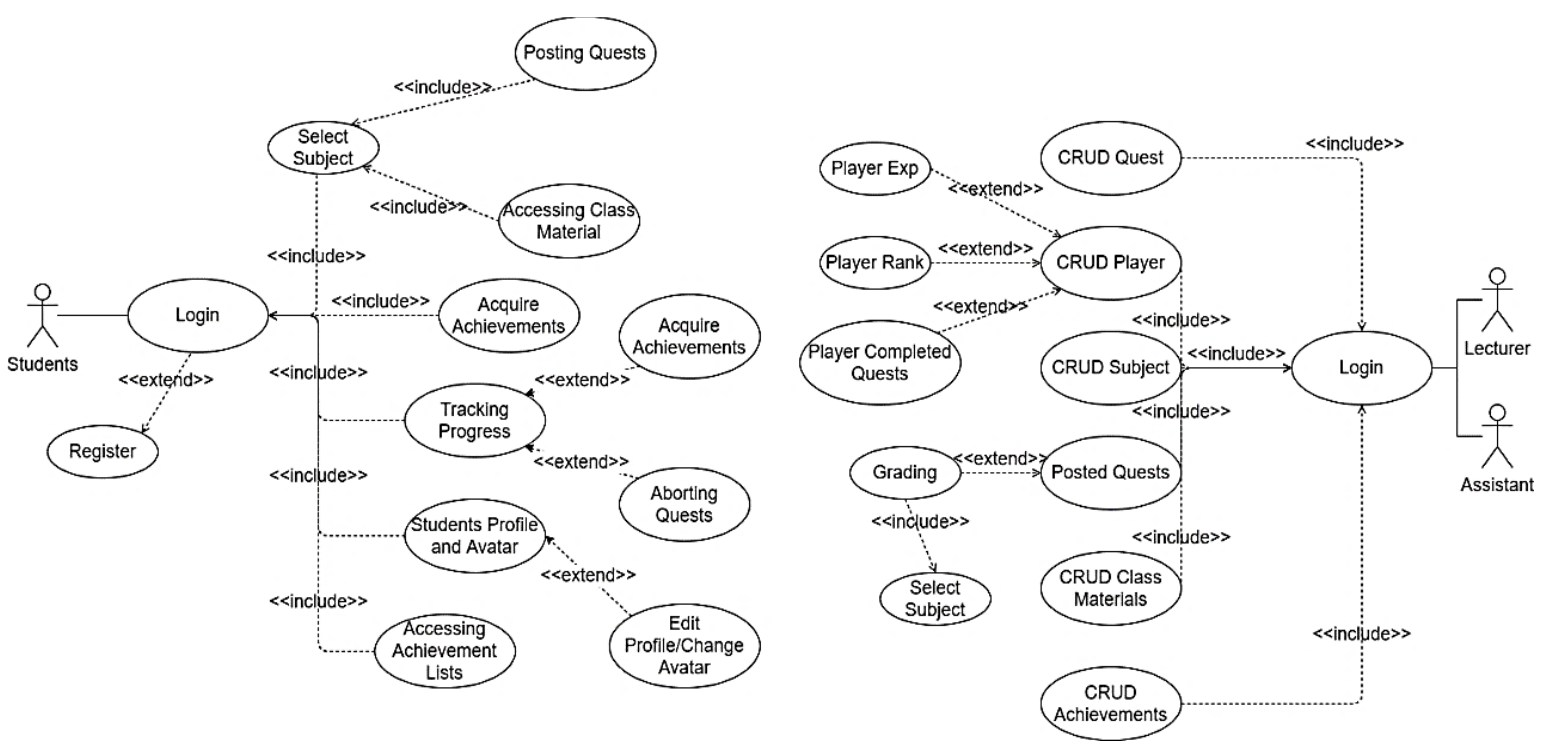

Figure 3. Use case diagram of Rimigs

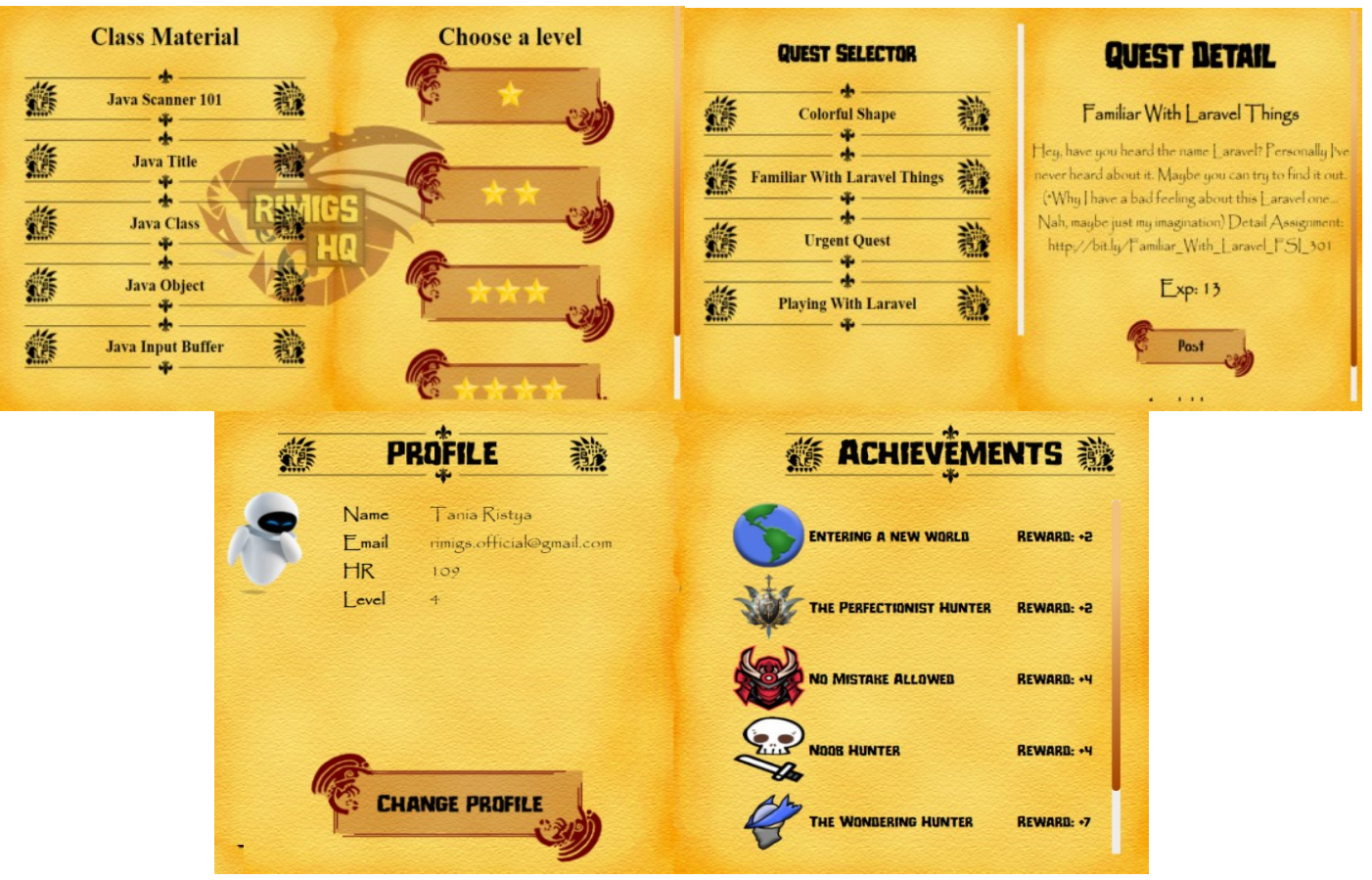

Figure 4. Rimigs user interface

\section{RESULTS AND DISCUSSION}

The number of samples in this research was determined based on the Slovin formula with a $5 \%$ margin of error. The minimum number of samples from the Slovin equation is 48, and 53 samples are used in this research. The descriptive analysis for this questionnaire is shown in Table 1. From Table 1, the standard 
deviation for each indicator is smaller than the mean. From the descriptive analysis, it can be said the spread out of the data is closer to the mean, which makes the distribution is less spread out. The validity of this questionnaire was determined with pearson product moment, and the Cronbach Alpha formula was used in the reliability of the questionnaire. The validity of this research questionnaire is shown in Table 2 .

The validity of the questionnaire is based on the corrected total item correlation score $>=$ the critical value. The critical value for each indicator is 0.276 for the degree of freedom 51 and $\alpha=0,05$. Based on Table 1, all the variable has a valid result. The reliability score for the questionnaire is shown in Table 3 . The reliability of the questionnaire is based on the Cronbach alpha score $>$ critical value. For this research, the critical value is 0.7 , and the Cronbach alpha score for each indicator is 0.917 for performance and 0.847 for motivation. Therefore, all the indicators have a reliable questionnaire. Figure 5 shows the difference between students learning with a gamification system and a group of students who learn with a non-gamification system.

Table 1. Descriptive analysis

\begin{tabular}{ccc}
\hline Descriptive analysis & Performance & Motivation \\
\hline Mean & 5.057 & 3.958 \\
Std. Dev & 1.035 & 0.840 \\
Minimum & 2 & 1 \\
Maximum & 5 & 5 \\
\hline
\end{tabular}

Table 2. Questionnaire validity result

\begin{tabular}{ccccc}
\hline Indicators & Variable & Corrected Total Item Correlation & Critical Value & Criteria \\
\hline Performance & A1 & 0.831 & 0.276 & Valid \\
& A2 & 0.749 & & Valid \\
& A3 & 0.842 & & Valid \\
& A4 & 0.759 & Valid \\
& A5 & 0.830 & Valid \\
& A6 & 0.869 & Valid \\
& A7 & 0.688 & Valid \\
& A8 & 0.833 & Valid \\
& A9 & 0.674 & Valid \\
& A10 & 0.487 & Valid \\
Botivation & B1 & 0.465 & & Valid \\
& B2 & 0.720 & Valid \\
& B3 & 0.606 & Valid \\
& B4 & 0.648 & Valid \\
& B5 & 0.732 & Valid \\
& B6 & 0.821 & Valid \\
& B7 & 0.733 & Valid \\
& B8 & 0.822 & Valid \\
& B9 & 0.738 & Valid \\
B10 & 0.588 & & Valid \\
\hline
\end{tabular}

Table 3. Questionnaire reliability result

\begin{tabular}{cccl}
\hline Indicators & Cronbach Alpha & Critical Value & Criteria \\
\hline Performance & 0.917 & \multirow{2}{*}{0.7} & Reliable \\
Motivation & 0.874 & & Reliable \\
\hline
\end{tabular}

In this research, the students are divided into two groups. One group will learn a programming subject with a non-gamification system (Group 1), and another group will learn a programming subject with a gamification system (Group 2). In group 1, not all the students pass or having a good grade in the programming class. Although most of the students have good grades, some of the students have bad grades. In another group, the lowest grades are B, and most students in this group have excellent grades. Based on Figure 5, a significant difference exists between a group that learns with a gamification system and a group that didn't. Figure 6 shows the students' motivation while using gamification in programming class.

The students' motivation is measured based on the group. The students are divided into two groups. One group will learn without Rimigs (Group 1), and the other group will learn with Rimigs (Group 2). Based on Figure 6, the motivated students in group 2 are higher than those in group 1. And also, the number of unmotivated students in group 2 is less than group 1. The result in Figure 6 indicates Rimigs has a positive impact, especially on increasing students' motivation. The core of accomplishment and ownership is the most impactful.

Rimigs: the impact of gamification on students' motivation and performance... (Ferdian Aditya Pratama) 


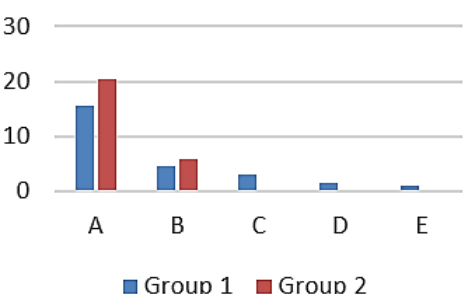

Figure 5. Students' performance

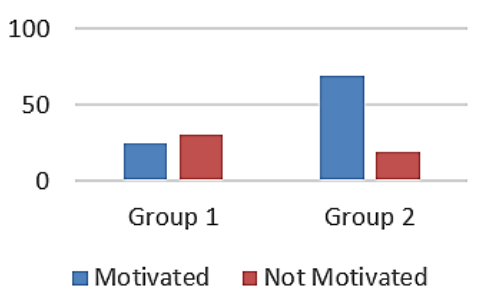

Figure 6. Students' motivation

\section{CONCLUSION}

The use of Rimigs as a gamification system in programming class turns out can help the students on their motivation in learning programming and help them get an excellent grade. Implementing both side cores in Octalysis is essential, but in Rimigs, the left-side cores in Octalysis have more impact on student's motivation. In this research, both students' performance and motivation increase significantly while learning programming subjects using Rimigs as the gamification system.

\section{REFERENCES}

[1] Y.-K. Chou, Actionable Gamification; beyond points, badges, and leaderboards, Octalysis Media, 2016.

[2] M. G. Guillen, J. Quist and J. Hamari, "Gamification of backcasting for sustainability: the development of the Gameful Backcasting Framework (GAMEBACK)," Journal of Cleaner Production, pp. 1-16, 2021, doi: 10.1016/j.jclepro.2021.126609.

[3] M. Najjara, S. A. Ghannouchi and S. Ghannouchi, "GaBPM: An attempt for the enhancement of BP performance through gamification," in CENTERIS - Int. Conf. ENTER. Inf. Sys., 2021, doi: 10.1016/j.procs.2021.01.237.

[4] N. Alsaleh and R. Alnanih, "Gamification-based Behavioral Change in Children with Diabetes Mellitus," in The 11th Int. Conf. Ambient Sys., Net. Tech., Warsaw, 2020, pp. 442-449, doi: 10.1016/j.procs.2020.03.087.

[5] N. H. b. M. Khir and MarinaIsmail, "Review on gamification in children computer interaction (CCI) for persona modelling," Bulletin of Electrical Engineering and Informatics, vol. 8, no. 4, pp. 1411-1417, 2019, doi: 10.11591/eei.v8i4.1622.

[6] S. Mishra and G. Malhotra, "The gamification of in-game advertising: Examining the role of psychological ownership and advertisement intrusiveness," International Journal of Information Management, vol. 61, no. 3, 2021, doi: 10.1016/j.ijinfomgt.2020.102245.

[7] N. Hawari, N. H. M. Zain and A. Baharum, "The need of gamified assessment for engaging learning experience," Bulletin of Electrical Engineering and Informatics, vol. 9, no. 2, pp. 722-728, 2020, doi: 10.11591/eei.v9i2.2083.

[8] J. Díaz-Ramírez, "Gamification in engineering education - An empirical assessment on learning and game performance," Heliyon, vol. 6, pp. 1-10, 2020, doi: 10.1016/j.heliyon.2020.e04972.

[9] C. Dichev and D. Dicheva, "Gamifying education: what is known, what is believed and what remains uncertain: a critical review," Int. J. Edu. Tech. Higher Education, vol. 14, no. 9, 2017, doi: 10.1186/s41239-017-0042-5.

[10] S. Sandrone and C. Carlson, "Gamification and game-based education in neurology and neuroscience: Applications, challenges, and opportunities," Brain Disorders, vol. 1, pp. 1-5, 2021, doi: 10.1016/j.dscb.2021.100008.

[11] K. Huotari and J. Hamari, "A definition for gamification: anchoring gamification in the service marketing literature," Electronic Markets, vol. 21, no. 1, pp. 21-31, 2017, doi: 10.1007/s12525-015-0212-z .

[12] M. E. Parra-González, J. López-Belmonte, A. Segura-Robles and A.-J. Moreno-Guerrero, "Gamification and flipped learning and their influence on aspects related to the teaching-learning process," Heliyon, vol. 7, pp. 1-10, 2021, doi: 10.1016/j.heliyon.2021.e06254 .

[13] F. F.-H. Nah, Q. Zeng, V. R. Telaprolu, A. P. Ayyappa and B. Eschenbrenner, "Gamification of Education: A Review of Literature," in Int. Conf. HCI in Business, 2014, pp. 401-409, doi: 10.1007/978-3-319-07293-7_39.

[14] N.-Z. Legaki, K. Karpouzis, V. Assimakopoulos and J. Hamari, "Gamification to avoid cognitive biases: An experiment of gamifying a forecasting course," Technological Forecasting \& Social Change, vol. 167, pp. 1-19, 2021, doi: 10.1016/j.techfore.2021.120725.

[15] K. Jahn et al., "Individualized gamification elements: The impact of avatar and feedback design on reuse intention," Computers in Human Behavior, vol. 119, pp. 1-13, 2021, doi: 10.1016/j.chb.2021.106702.

[16] M. Tesar, "Towards a post-Covid-19 "New Normality?": Physical and social distancing, the move to online and higher education," Policy Future in Education, vol. 18, no. 5, pp. 556-559, 2020, doi: 10.1177/1478210320935671.

[17] Sukendro, A. Habibi, Khaeruddin, B. Indrayana, Syahruddin, F. A. Makadada and H. Hakim, "Using an extended Technology Acceptance Model to understand students' use of e-learning during Covid-19: Indonesian sport science education context," Heliyon, vol. 6, pp. 1-9, 2020, doi: 10.1016/j.heliyon.2020.e05410.

[18] B. Morschheuser, L. Hassan, K. Werder and J. Hamari, "How to design gamification? A method for engineering gamified software," Information and Software Technology, pp. 219-237, 2018, doi: 10.1016/j.infsof.2017.10.015. 
[19] B. Morschheuser, A. Maedche and D. Walter, "Designing Cooperative Gamification: Conceptualization and Prototypical Implementation," in 20th ACM Conference on Computer-Supported Cooperative Work and Social Computing, Portland, 2017, doi: 10.1145/2998181.2998272.

[20] N.-Z. Legaki, N. Xi, J. Hamari, K. Karpouzis and V. Assimakopoulos, "The effect of challenge-based gamification on learning: An experiment in the context of statistics education," International Journal of Human-Computer Studies, vol. 144, pp. 1-14, 2020, doi: 10.1016/j.ijhcs.2020.102496.

[21] F. Cechella, G. Abbad and R. Wagner, "Leveraging learning with gamification: An experimental case study with bank managers," Computers in Human Behavior Reports, vol. 3, pp. 1-9, 2021, doi: 10.1016/j.chbr.2020.100044.

[22] P. Buckley and E. Doyle, "Individualising gamification: An investigation of the impact of learning styles and personality traits on the efficacy of gamification using a prediction market," Computers \& Education, vol. 106, pp. 43-55, 2017, doi: 10.1016/j.compedu.2016.11.009.

[23] T. Ouariachi, C.-Y. Li and W. J. L. Elving, "Gamification Approaches for Education and Engagement on ProEnvironmental Behaviors: Searching for Best Practices," Sustainablility, vol. 12, no. 11, 2020, doi: $10.3390 / \mathrm{su} 12114565$

[24] J.-M. Campillo-Ferrer, P. Miralles-Martínez and R. Sánchez-Ibáñez, "Gamification in Higher Education: Impact on Student Motivation and the Acquisition of Social and Civic Key Competencies," Sustainability, vol. 12, no. 12, 2020, doi: 10.3390/su12124822.

[25] N. L. Mingoc and E. L. R. Sala, "Design and Development of Learn Your Way Out: A Gamified Content for Basic Java Computer Programming," in The Fifth Information Systems International Conference 2019, 2019, pp.10111018 doi: 10.1016/j.procs.2019.11.211.

[26] O. J. Okesola, A. A. Adebiyi, A. A. Owoade, O. Adeaga, O. Adeyemi and I. Odun-Ayo, "Software Requirement in Iterative SDLC Model," in CSOC 2020: Intelligent Algorithms in Software Engineering, 2020 pp. 26-33, doi: 10.1007/978-3-030-51965-0_2.

\section{BIOGRAPHIES OF AUTHORS}

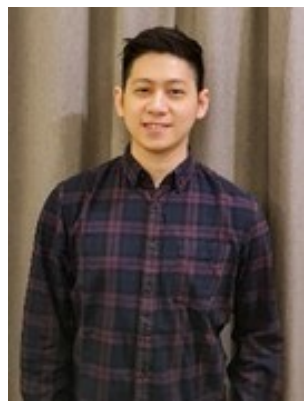

Ferdian Aditya Pratama was born in Semarang, Indonesia in 1993. He received his Bachelor's Degree in Informatics Engineering in 2014 and his Master Degree in Computer Science in 2016 from Satya Wacana Christian University. Currently, he is working as an Assistant Professor at Atma Jaya Catholic University of Indonesia. He has a research interest in software engineering and human-computer interaction.

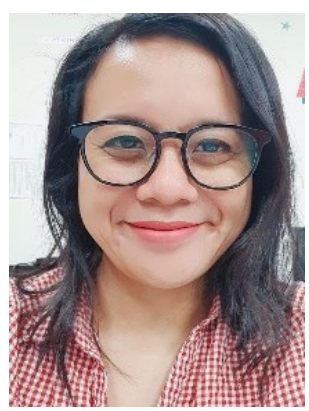

Riana Magdalena Silitonga was born in Bandung, Indonesia in 1978. She received her Bachelor's Degree in Mathematics in 2001 and her Master Degree in Management Technology in 2003 from Bandung Institute of Technology. Currently, she is a Ph.D student in the Department of Industrial and Systems Engineering of Chung Yuan Christian University, Taiwan. Her research interest is in management technology, information system, product design and innovation.

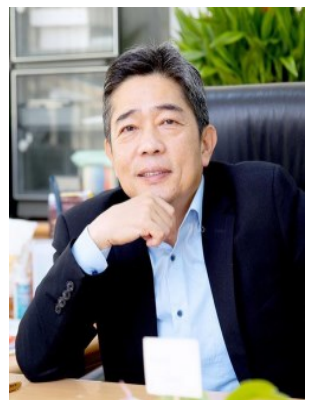

Yung-Tsan Jou was born in Kaoshiung, Taiwan in 1963. He received his Master Degree of Mechanical Engineering in 1995 and Ph.D in Integrated Mechanical Engineering and Industrial Engineering in 2003 from Ohio University, USA. Currently he is an Associate Professor at Department of Industrial and Systems Engineering Chung Yuan Christian University, Taiwan. He has published over 100 technical papers and reports, and 3 patents, and has translated 2 books. He has been involved in many research projects since he joined the department in 2004 and has received significant amount of research grant from various sources, including the National Science Council, Chung-Shan Institute of Science \& Technology, Industry Technology Research Institute, Chung-Yuan Christian University, and companies from the Industry. His research interest is virtual reality and ergonomics, design of innovative human-machine interfaces, new product design, smart manufacturing, machine learning, and data analysis. 